\title{
Spinoza's Thinking Substance and the Necessity of Modes
}

\author{
KAROLINA HÜBNER \\ University of Toronto
}

\section{Introduction}

In Spinoza's metaphysics the term "substance [substantia]" names, in line with a long tradition, what is ontologically most fundamental. ${ }^{1}$ That is, Spinoza holds that if there is anything at all-individuals, properties, relations, etc.- there is substance, or a conceptually and existentially selfsufficient entity. As is well known, Spinoza also holds that it can be demon-

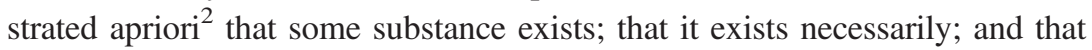
there is, and can be, only one substance. In this paper I want to show that Spinozistic substance has two further properties: namely, it must be modified $^{3}$ and thinking. While Spinoza's arguments for the existence of substance and for substance-monism (i.e., the claim that only one substance can exist) have already received considerable attention, much less attention has been paid to what, if any, arguments Spinoza has for the existence of "modes" (the non-essential, dependent properties of substance) and for the existence of "attributes" (the basic kinds of being possessed by substance, of which we know two: thought and extension). ${ }^{4}$ Moreover, the readers who first posed these two questions - Spinoza's British and German Idealist commentators, in the $19^{\text {th }}$ and early $20^{\text {th }}$ centuries-have by and large found

1 For the roots of this tradition see Aristotle Meta.1019a2-4, 1069a18-20; Cat.2b6-7. I will say more about how Spinoza understands ontological dependence in $\S 2$; see also Gill 1989:3; Schaffer 2009.

2 I will use "apriori" here in the later Kantian sense of (roughly) 'without appealing experience'. For other uses of this term in this sense in relation to Spinoza, cf. e.g. Bennett 1984:111; Curley 1969:99; Jarrett 2007:89; Manning 2012:6.2; Scruton 2002:49.

3 More precisely it is a matter of substance's self-modification or self-determination. I will for the most part leave this qualification implicit in what follows.

$4 \quad$ I look at existing discussions in $\$ 3$. On Spinoza's substance-monism, see e.g. Bennett 1984; Carriero 2002; Della Rocca 2002, 2006, 2008; Garrett 1990; Nadler 2006. 
Spinoza's account to be severely lacking. Many of them concluded that Spinoza simply fails to demonstrate that there must be anything other than an undifferentiated substance, and that he does so either intentionally or because of the insufficiency of the conceptual resources at his disposal.

Now, it is certainly true that many of Spinoza's doctrines (especially his psychological and ethical doctrines) suggest an underlying commitment to ontological diversity in nature. ${ }^{5}$ But from the point of view of Spinoza's future Idealist critics, this commitment can seem like no more than an unjustified assumption. And there are at least two more specific reasons to think that Spinoza would agree with the Idealists that both the existence of things distinct from substance (i.e. modes) and the existence of different kinds of being (attributes) demand demonstration. In the first place, both claims are subject to formal proofs in the Ethics, in E1p16d and E2p1d-2d respectively (although as we shall see these proofs are not entirely successful). Secondly, if Spinoza indeed fails to demonstrate the necessity of either kind of ontological diversity, such a failure would violate his own commitment to the Principle of Sufficient Reason (PSR). This commitment is a key component of Spinoza's conception of intelligibility. It is expressed as the claim that everything (even what we would nowadays term 'negative facts') can be "conceived" or, in an alternate formulation, given a "cause or reason [causa sive ratio]" for its existence and nature (E1ax2, E1p11altd1). ${ }^{6}$ Given this commitment, the Idealists are right to demand from Spinoza reasons why substance must be extended, thinking, and modified.

In what follows I want to focus on the way that Hegel put the charge in his Lectures on the History of Philosophy:

How does it come that besides [substance] there now appears the [mode of] understanding, which applies to absolute substance the two forms of thought and extension? and whence come these two forms themselves?... The greatest difficulty in Spinoza is. . to grasp the relation of this determinate to [substance]...[E]specially in regard to the attributes, there is no necessity evident, why these are thought and extension in particular. (1995:264, 267-9; emphasis added). ${ }^{7}$

5 For emphasis on this fact see Melamed 2010a, 2013.

6 The second formulation reflects the fact that for Spinoza conceiving of a thing requires us to conceive of its causes (see E1ax4).

On the role of PSR in Spinoza's philosophy, see Della Rocca 2003, 2008.

7 See also 1969:98; 1995:269; Caird 1888:142; Joachim 1901:103, 106, 108, 220; Martineau 1882:185.

Given limited space I cannot examine the different Idealist readings in detail. For further discussion see e.g. Förster and Melamed 2012; Franks 2005; Melamed 2010, 2013; Newlands 2011, 2011b; Parkinson 1993; also Hübner forthcoming-b.

In the passage cited Hegel hints at a 'subjectivist' interpretations of the attributes, on which the latter are illusions attributed to substance by finite minds (cf. Caird 1888:53-4; Wolfson 1934:146). For discussion, see Gueroult 1968; Jarrett 1977b; Newlands 2011b; Shein 2009:2. 
In this paper I want to outline one possible way to respond to these questions from within Spinoza's own metaphysical framework: that is, I want to show how Spinoza could successfully establish the necessity of ontological diversity-both the diversity that comes with the existence of things distinct from substance, and the diversity that comes with the existence of different kinds of being. To wit, I want to show, first, that it can be demonstrated apriori that in Spinoza's view there can be no unmodified substance, i.e., that every Spinozistic substance must be determined by a dependent entity - a non-essential property (a mode). In other words, I will argue that according to Spinoza not only must substance exist, but it must have modes, such that modes, too, must exist. I will claim moreover that this necessary existence of modes is implicit already in Spinoza's official definition of "substance" in the Ethics, once we grant his basic commitments to a substance-attribute-mode ontology, to his conception of intelligibility, and to necessitarianism.

The second main claim I will make in the paper is that within the framework of the Ethics it is equally demonstrable apriori that there can be no substance that is not a thinking substance. That is, I will show that there can be no Spinozistic substance that is not engaged in the activity of "conceiving", or in bringing about the existence of ideas or modes of thought. ${ }^{8}$ To be sure, most (if not all) commentators accept that Spinozistic substance must think insofar as it must instantiate all basic kinds of being or attributes, and thus also thought. What I will show, however, is that the conclusion that substance is necessarily a res cogitans is (i) also implicit already in the definition of substance, once we assume the aforementioned basic three commitments of Spinoza's metaphysics; and that this conclusion (ii) rests on reasons that have to do with thought specifically as a kind of being, not with its shared ontological status as an "attribute". In other words, I will argue that in Spinoza's framework thought stands in a unique and ontologically fundamental relation to substance (and so to being as such), such that even if (per impossibile by Spinoza's lights) there were multiple substances, or an unextended substance, such substances too would have to be thinking things. In contrast, to my knowledge at least, heretofore the claim that Spinozistic substance must think has always been established on the grounds that, if valid, would be valid for every attribute-and so, for example, for extension as much as for thought. And although this way of arguing does succeed in securing the conclusion that Spinozistic substance must think, it does so in a way that obscures another important result, namely the fact that for Spinoza thought has a more fundamental relation to substance qua substance than any other attribute. This inseparability of thought from substantiality confirms that for Spinoza thought has an outsized role when

For the claim that Spinoza distinguishes "conception" from "thought" and "ideas" see Newlands 2012. For textual evidence for the equivalence of these terms see $\$ 2.2$. 
compared to other kinds of being (as has often been suggested by commentators). ${ }^{9}$ I see the reading I am proposing in this paper as shoring up this interpretative tradition, and doing so for a new reason.

Against the background of Idealist criticisms, to show that Spinozistic substance necessarily has these two properties - that it is both necessarily modified (or, more precisely, self-modified) and necessarily thinking-is one way we can address worries about the completeness of Spinoza's system. However, one may object that to ask 'Why must there be thought?' is simply the wrong question to pose within Spinoza's framework. For (the objection goes) the existence of thought is an empirically ascertainable fact, as Spinoza himself acknowledges (E2ax2,4-5). When it comes to the relation of substance to thought, in Spinoza's framework the relevant questions to pose are instead, (i) To how many substances does thought belong?; and, (ii) Does it belong to the same substance to which extension belongs?. In other words, one may object that the real challenge as regards the relation of substance to thought in Spinoza's metaphysics is to establish the necessity not of thought but of substance-monism, and with it the necessity of a single substance having a multiplicity of attributes. I believe, however, that both kinds of questions are worth asking. And while Spinoza's argument for substance-monism has received a great deal of attention already, Hegel's question-Why must there be thought (and extension) in particular?-has been relatively neglected.

Let me say a few words about how the paper will unfold. The next two sections are preparatory: in $\$ 2$ I review the most relevant Spinozistic doc-

See e.g. Caird 1888:202; Della Rocca, 2003a, 2008; Martineau 1882:189; Pollock 1880:173-4, 182; and Newlands 2012 for dissent.

Many commentators have argued for (or worried about) this metaphysical 'privilege' of thought on the grounds that there seem to be more modes in the attribute of thought than in other attributes (see e.g. Curley 1969; Joachim 1901:72; Melamed 2012; Nadler 2003:126, Newlands 2012). Unlike many scholars, I do not think that such numerical 'lopsidedness' is in itself a problem, as long as (1) the modes of different attributes can be appropriately related through identity (E2p7s); and (2) as long as no attribute depends causally or conceptually on another (E1p10\&s). According to others the privilege of thought manifests itself in the fact that the definition of an attribute notoriously makes a reference to "intellect" and to "conceiving"; this, it has been suggested, renders all attributes dependent on thought, contrary to their alleged conceptual self-sufficiency (E1p10). (See e.g. Bennett 1984:62; Martineau 1882:188, Pollock 1880:184, 187; Newlands 2011b, 2012.) To this list of thought's metaphysical prerogatives we could add here Spinoza's claim that substance's "power of thinking" is "equal" to the causal power responsible for its production of the whole of formal reality, under all the attributes (E2p7c). We should also note thought's ethical privilege: e.g. the Ethics' stated goal is the blessedness of the human "mind" (E2pref); our summum bonum is knowledge (E4p28).

I'm unconvinced by Laerke's objection (directed at Della Rocca's reading) that "conception" cannot be ontologically fundamental because for Spinoza concepts are merely modes, and so by definition grounded in something else (2011:454). This seems to overlook the fact that thought also constitutes a substantial attribute, and to this extent is ontologically fundamental and self-grounding. 
trines; in $\S 3$ I survey extant explanations for why Spinozistic substance must be modified and thinking. In $\S 4$, which constitutes the core of the paper, I offer an alternative argument for these two claims. $\$ 5$ contains several clarifications and responses to potential objections. I conclude in $\S 6$ with some brief remarks about the repercussions of my account for the status of Spinoza's definitions.

One final caveat: in this paper I hope to shed a new light on some basic ontological problems in Spinoza's metaphysics - namely, on the nature of substance and on its relations to modes and attributes. However, my aim is not to try to reconstruct Spinoza's intentions, or to clarify the arguments he actually gives. Rather, it is to draw out the implications of his concepts in a way that helps us fill in or supplement some of the gaps, or alleged gaps, in his demonstrations.

\section{Some Background}

Let me begin with a brief (and highly selective) overview of those of Spinoza's metaphysical commitments that will prove most relevant to our inquiry. There are three doctrines in particular that merit our attention. These are Spinoza's commitments to (i) essentialism and with it to a particular understanding of definitions; (ii) a substance-mode-attribute ontology; and, finally, (iii) necessitarianism. I will discuss each of these in turn.

\section{1 .}

Spinoza can be described as a card-carrying essentialist in the following sense: in his view all things have at least some essential properties (cf. E2def2). This is what explains the importance of "definitions" for Spinoza's metaphysics. For, as Spinoza states repeatedly, a good definition is one that states the definiendum's "essence [essentia]". ${ }^{10}$ Somewhat speculatively, we can gloss this as the claim that a definition is a proposition describing the property, or set of properties, necessary and sufficient for the actual existence and for an adequate conception of the definiendum (cf. E2def2). ${ }^{11}$ It is worth emphasizing here that in contrast to some contemporary views, for Spinoza not every necessary property of a thing counts as part of its essence. ${ }^{12}$ The

\footnotetext{
10 E2def2; TIE[93, 95, 96], E1p8s2 (II/50), E3p4d, E1p16d, E1p19d, E1p33s1 (II/74).

11 Cf. Bennett 1984:§54.4; Crane and Sandler 2005:194.

The "actual" existence of a thing refers to its in fact having been produced by substance (for finite things, this will also involve existing in duration), such that it no longer exists merely qua "formal essence", that is, an eternal but indiscernible implication of God's essence (cf. E2p8c\&s, KV2.20[3]note c [I/97]).

For Spinoza every actual essence is also a causal "potentia" (E3p7d, E1p34). This feature of Spinozistic essences will not play a role in our inquiry, but see e.g. Deleuze 1990; Hübner 2015; Viljanen 2011.
} 
necessary properties of a thing that are part of its essence are only those properties that are necessary and sufficient for the thing in question to be conceived and given as an actual existent.

Given this understanding of the nature of a definition, how Spinoza defines "substance" and "mode" - the only kinds of entities he takes to be metaphysically possible (E1p4d) — will tell us how he understands their essential natures. ${ }^{13}$ I cite the two definitions in their entirety:

By substance I understand what is in itself and is conceived through itself, i.e., ${ }^{14}$ that whose concept does not require the concept of another thing, from which it must be formed [quod in se est et per se concipitur hoc est id cujus conceptus non indiget conceptu alterius rei a quo formari debeat] (E1def3).

By mode I understand the affections of a substance, or that which is in another through which it is also conceived [substantiae affectiones sive id quod in alio est, per quod etiam concipitur] (E1def5).

One of the first things one may notice about these definitions is their quasi-symmetrical structure: both characterize their definienda first from the perspective of how the entity in question is, and, secondly, from the perspective of how it is conceived. ${ }^{15}$ And so a "substance" is what is essentially both "in itself" (that is, what is able to exist, or have being, independently of any other thing) ${ }^{16}$ and what is conceivable without the help of the concept of any other thing. ${ }^{17}$ The reverse is true for any

Cf. Garrett 1991:201; Carriero 1995; Steinberg 1987:189.

Spinoza seems to read metaphysical possibility directly off conceptual possibility, but the latter does not easily map onto what today we might take to be logically possible. Spinoza says very little explicitly about his logical views; for accounts see e.g. Bennett 1984, Donagan 1988:73-5; Garrett 1991:194; Hübner 2015; Newlands 2012, 2013; Steinberg 1987:194-5; Wilson 1999.

I do not take the clause following "i.e." to reduce both of the relations described in the preceding clause (ending with "i.e.") to conceptual relations, but only to either (1) elaborate on the meaning of being "conceived through" oneself or (2) draw out a consequence of that entire preceding clause. But see Newlands 2013:1.2 for dissent. On what may motivate this structure see e.g. Gueroult, 1968/1974; Hübner forthcominga; Melamed 2012, 2013. Cf. Aristotle, Cat.2a12-2a17; Descartes Pr 1.51, Second Replies (AT7.61).

Cf. Descartes: "all philosophers" agree that substance must be understood "apart from" a mode; to have the conception of substance we do not need to have "at the same time" a "conception" of something else (Comments on a Certain Broadsheet; AT 8B 350; cf. $\operatorname{Pr} 1.61)$.

Both substantial criteria are amenable to weaker and stronger readings: on the weaker, negative reading, to be "conceived through itself" means merely "not needing the concept of another thing for conception"; and being "in oneself" means merely "not needing another thing to exist" (cf. e.g. Curley 1969). On the more robust, positive reading, these 
"mode", on both counts: a mode is what requires some other thing in order to have being ${ }^{18}$ (i.e., it exists because and in the sense that it modifies or determines another thing), and the concept of another thing to be conceived.

In short, what distinguishes the two metaphysically possible kinds of entities for Spinoza is their possession or lack of ontological and conceptual independence. ${ }^{19}$ As is suggested by E1def5's characterization of a "mode" as an "affection", the sort of dependence relation Spinoza has in mind here seems to be akin to the relation of a property to the thing that bears this property. ${ }^{20}$ Thus we can understand Spinozistic modes not just-rather abstractly_as 'ontologically dependent' entities, but, slightly more precisely, as determining, modifying, and affecting what grounds them (or, still more precisely: as ways that substance determines, modifies, and affects itself).

According to Spinoza, necessarily, only one entity ("God", or a substance unlimited in every kind of being) satisfies the definition of substance (E1p14, E1def6). This is Spinoza's aforementioned, and tradition-bucking, doctrine of substance-monism. ${ }^{21}$ Everything else that exists - and, in Spinoza's view there necessarily exists an "infinity" of things (E1p16) - is a mode.

criteria mean, respectively, being "self-explanatory" (cf. e.g. Curley 1969:40; Della Rocca 1996:4, 2002:12, 2006:18; Newlands 2013:2), and "self-grounding" or "self-caused" (cf. e.g. Lin 2006, Scruton 2002:53). Arguably, we need to factor in Spinoza's commitment to the PSR to establish the stronger readings (cf. Curley 1969:40). For the purposes of this paper it is irrelevant which reading of inherence we choose, but we will have occasion to refine what conception per se means in $\$ 5$. The possibility of self-grounding (or self-causation) has of course been rejected by many; see e.g. Arnauld, AT 7.210; Curley 1969:41; Schaffer 2009.

See Della Rocca, 2003a, 2006, 2008 for an account on which the "being-in" (or "inherence") relation is reducible to the "conceive-through" relation. For other accounts of inherence see e.g. Carriero 1995; Curley 1969; Donagan 1988; Garrett 2002; Jarrett 1977; Melamed 2009, 2013. For other accounts of conception see references in note 13; Laerke 2011; Melamed 2009, 2013; Newlands 2012.

Cf. Donagan 1988:72; and Aristotle, Cat.1a23-25 ("By 'in a subject' I do not mean what is in something as a part, but rather what is unable to exist apart from that in which it is").

19 Cf. Curley 1969:38; Jarrett, 1977a.

According to Spinoza it is not possible that something could exist in itself but be conceived through another, or exist in another but be conceived through itself. I will not rehearse the argument here but see e.g. Curley 1969; Jarrett, 1977a; Lin 2006:145.

Cf. e.g. KVI.i[8]note d (I/17); E1p17s[I] (I/62); E1p16d; Bayle 1991; Carriero 1995; Jarrett, 1977a; Melamed 2009, 2013; Newlands 2013:1.2; see Curley 1969 for an influential dissent.

For discussion of Spinoza's monism see references in note 4. 
It will also prove relevant for our purposes that Spinoza recognizes both finite and infinite modes. But to clarify the distinction between these, I first need to say something more about Spinoza's notion of "attribute".

\section{2 .}

The most important feature of a Spinozistic attribute is that it "constitutes" (a) substance's essential nature (E1def4). ${ }^{22}$ As is well known, Spinoza owes much of his thinking on this point to Descartes's notion of a "principal attribute" $(\operatorname{Pr} 1.53)$. However, as is also well known, he departs from his predecessor in a number of ways. First and foremost he does so by holding that substance can possess more than one essential nature. ${ }^{23}$ Indeed, Spinoza's God possesses "infinite" — all possible ${ }^{24}$ _attributes (E1def6). However, given that according to Spinoza our minds are essentially intentionally directed at what is extended (E2p13, E2ax5), and hence limited to a knowledge of bodies and of ideas of bodies, ${ }^{25}$ we apprehend God solely as essentially extended and as essentially thinking.

Another important feature of Spinozistic attributes has to do with their relation to thought. For Spinoza to "think [cogitare]"-or, what for Spinoza is terminologically equivalent, to form a "concept", an "idea", or a "cognition" 26 - is for a thinking thing to "act" (E2def3), i.e. to produce an effect. ${ }^{27}$ Attributes become relevant in this context because according

22 I will stay neutral here on the question whether each attribute constitutes a distinct essence of substance (see Donagan 1973). I also will not argue here for specific readings either of the relation of "constitution", or of the meaning of E1def4's reference to an intellect, but with other critics of the subjectivist reading of the attributes (see note 5), I assume that the intellect's perception is veridical.

See Pr.1.53. Cf. de Vries, Ep8 (IV/41). See E1def6expl, KV I.2[1] (I/19); cf. Bennett 1984:75-7; Garrett 1991:215n2. For discussion see Melamed 2012, 2013.

See e.g. E1ax5 ("intelligi...sive...conceptus involvit”); E2p19d-20\&d, E2p22d-25d ("idea sive cognitio"); $\mathrm{E} 2 \mathrm{p} 49 \mathrm{~d} \& \mathrm{~s}[\mathrm{II}]$ (II/130-1) ("conceptum sive ideam", "ideam sive mentis conceptum"); E5p23d ("conceptus seu idea"). On the synonymity of there terms cf. Della Rocca 1996, 2002:12; Lin 2006:145; Wilson 1999. For dissent, see Newlands 2012.

Strictly speaking an "action" for Spinoza is an effect produced "adequately" (i.e., autonomously) (E3def2). Pace Laerke (2011:454n56) I don't think that E2def3 should be read as implying that all ideas are formed by "minds", a term Spinoza arguably reserves for finite thinking things (cf. Renz 2011). This is so for at least two reasons: (1) Ontologically "minds" are "parts" of the substantial "infinite intellect" (E2p11c). So if some idea were formed by a mind, it would also be true to say that it was formed by the infinite intellect. (2) If only minds could form concepts, the fact that Spinoza's definition of substance makes reference to substance being "conceived through itself" would make substance essentially dependent on finite modes. In addition, (3) some scholars (e.g. Della Rocca 2003b) question the possibility of genuine finite "actions". If this is how Spinoza understands the sense in which concepts are "actions" in E2def3, then we have further reason to attribute them to the infinite intellect rather than to (finite) minds. 
to Spinoza (who, once again, is following Descartes here [Pr.1.53]) all thinking takes place in terms of irreducible and mutually exclusive concepts corresponding to the attributes. So all thinking of particular bodies, movements, and rests requires us to make use of the concept "extension". Likewise, all thinking of particular representations, volitions, emotions and doubts involves the concept "thought". But neither "thought" nor "extension" are further explicable by any more fundamental shared concept. On this account, entities under different attributes-for example, a particular body and a particular mind-are thus conceptually radically disparate $\left(E 1 p 10\right.$, E2p5-6). ${ }^{28}$ So although Spinoza is committed to the idea that reasons can be given for the existence and nonexistence of every thing, he also holds that only extended things qua extended can supply reasons for what happens in the realm of bodies, and that only thinking things qua thinking can for supply reasons for what happens in the realm of ideas. The doctrine in question is often referred to as Spinoza's inter-attribute "barrier". 29

With the concept of attribute on the table, we are now in a position to explain the distinction between finite and infinite modes. Most simply put, finite modes are things familiar from ordinary experience: bees, rocks, trees, etc. More precisely, something is a finite mode when its essential ontological dependence qua mode (ultimately on substance) is mediated by other things of the same attribute-kind. (For example, a given body is finite because it is bound by other extended things and determined by them to exist, to move and to rest [E2def1, E1p28].) ${ }^{30}$ Conversely, a mode is infinite when it is a modification of substance's essential nature unlimited by other things of the same kind. Spinoza gives few examples of infinite modes, but the one that is most relevant for our purposes is "God's infinite idea", the idea representing all that is $(\mathrm{E} 2 \mathrm{p} 8 \& \mathrm{c}, \mathrm{E} 2 \mathrm{p} 3-4){ }^{31}$

28 Both thought and extension have arguably that in common that they are "attributes", "manifestations of substantial essence", etc. However, such concepts are not concepts of real things (of modes or of substance); they are merely abstract generalizations. On the distinction between the two kinds of ideas see Hübner forthcoming-c.

The textual situation is slightly more complex than this summary suggests. In particular, despite E1p10, Spinoza holds that we can make some true claims about things under one attribute on the basis of our knowledge of things under a different attribute (see e.g. E2p13s). For discussion of this problematic claim see Della Rocca 1996:20-1.

For a more detailed account of Spinoza on finitude and negation see Hübner forthcoming-b.

31 The more well known example of such a mode is "motion and rest" (Ep.64).

Although I cannot defend my interpretation in detail here, I suggest that we identify this "infinite idea" with the mediate infinite mode, i.e. with the "varying" "face of the whole universe" (Ep.64) under the attribute of thought. (Like Schmaltz 1997:223, I disagree with the standard reading of this "face" as the mediate mode of extension alone.) 
Let me conclude this brief survey of Spinoza's metaphysical commitments with a comment about his necessitarianism. ${ }^{32}$ First of all, we should note that for Spinoza the necessity that governs nature involves conceptual necessity (though how exactly to flesh out the relevant conceptual relations, and how to characterize their relation to causality, are controversial matters). ${ }^{33}$ The modal status of finite modes is likewise a subject of controversy. ${ }^{34}$ Fortunately, for the purposes of this paper, we can remain noncommittal about Spinoza's modal views on finite things while assuming what is nearly universally granted, namely that Spinoza is a strict necessitarian about the infinite features of nature - that is, about substance, attributes, and infinite modes. ${ }^{35}$ When it comes to these infinite features Spinoza's position clearly is that - to put it in Leibnizian terms - there is only one metaphysically possible world: ${ }^{36}$ anything that is genuinely metaphysically possible is also necessary and actual (that is, necessarily brought into existence by substance). Thus, ${ }^{37}$ for Spinoza, there are no merely possible substances: no substance other than God can exist or even be conceived (E1p14), while God exists necessarily because, and in the sense that, his essence entails his existence (E1p7, E1p11\&d, E1p19d, E1p24d). Moreover, since God is defined as the substance of "infinite", or all, attributes, there can be no attributes other than those actually instantiated by God. ${ }^{38}$ So also the attributes that exist are necessary. Indeed, for them to have differed either in nature or in quantity is for God himself to have

The infinite idea "varies" as the eternally existing formal essences of modes come to be actualized in duration (and so as the representations of these essences come to "involve... existence") and then cease to exist (E2p8c\&s).

The Ethics mentions also an "infinite intellect" (E1p16\&d, E2p4d, E2p7s, E2p11c, E5p40s, cf. Ep.64). The relation between the infinite idea and the infinite intellect is a matter of controversy; for accounts see e.g. Della Rocca 1996:38ff; Giancotti 1991; Gueroult, 1968/1974; Melamed 2013; Schmaltz 1987.

See E1p16, E1p17s[I] [II/62], E1p29, E1p33, Ep. 75. Cf. Leibniz, On Freedom (AG 94). For more detailed accounts see Garrett 1991; Koistinen 1998, 2003; Newlands 2010, 2013.

See references in note 13 .

See e.g. Bennett 1984; Curley 1969; Curley and Walski 1999; Garrett 1991; Huenemann 1999; Koistinen 1998; Newlands 2013; Steinberg 1987.

See e.g. Bennett 1984:111-2; Curley 1969: 107; Garrett 1991:192, Huenemann 1999:224-5; Koistinen1998, 2003:285, Newlands 2013.

Spinoza does not to my knowledge explicitly characterize attributes as "infinite", but presumably something that "expresses" and "constitutes" the essence of something infinite is itself also infinite. Cf. also E2p1s.

Cf. Bennett 1984:111-2; Koistinen 1998:71; Newlands 2013; Steinberg 1987; and E1p17s[I] (II/62).

From here to the end of the paragraph my account is indebted to Garrett 1991:214-5n2.

Cf. Huenemann 1999. 
had a different nature, something Spinoza explicitly rules out as absurd (E1p33d). Finally, Spinoza is equally explicit that infinite modes are necessary (E1p21-2; E2p11d) (albeit here, unlike in the case of substance, the source of the necessity is external to each mode per se). ${ }^{39}$ More precisely, since infinite modes are implied and caused (either immediately or mediately) by substance's essential nature, they exist necessarily insofar as something that follows necessarily from what exists necessarily (as substance does) also exists necessarily. ${ }^{40}$ Since attribute could not have been different, nothing different could have followed from them than what actually does follow. So also every infinite mode in Spinoza's metaphysics exists necessarily, and there could not have been infinite modes other than the ones that actually exist.

Collectively, these assertions make up Spinoza's necessitarianism about

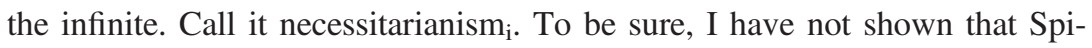
noza has the right to make any of these assertions. But all I wish to establish here is that he holds the above views, and so can be accurately described as adhering at least to this limited form of necessitarianism.

\section{Extant Explanations}

With the relevant parts of Spinoza's metaphysical picture now in view, let me turn to existing arguments - both Spinoza's own and others'-for the two claims I wish to establish in this paper, namely for the claims that Spinozistic substance is necessarily both thinking and modified.

I will start with the problem of the necessity of modes.

\section{1 .}

The Idealist charge as regards modes is, we can recall, that Spinoza asserts the existence of modes dogmatically, without demonstrating why it must be the case that there are beings distinct from substance-why substance cannot remain completely indeterminate, or undifferentiated. Prima facie at least the charge seems to stick. For in the Ethics Spinoza's demonstration of the proposition that modes must follow from substance-E1p16 - indeed seems to be little more than a simple assertion. $^{41}$ In its defense Spinoza cites the following principle: a thing's

38 Cf. "God's attributes are eternal" (E1p19); "[b]y eternity I understand existence itself, insofar as it is conceived to follow necessarily from the definition alone of the eternal thing" (Eldef8).

39 Cf. E1p33s1; and Newlands 2013.

40 As Newlands notes (2013:1.2.2), this is reminiscent of a contemporary modal axiom: $(\square \mathrm{p} \mathrm{\&} \square(\mathrm{p} \rightarrow q)) \rightarrow \square \mathrm{q}$. I assume here that the "following" relation is, minimally, inferential; for a fuller account see Hübner 2015. 
degree of "reality", or metaphysical "perfection" (E2def6), is proportional to the number of its properties:

intellect infers from the given definition of any thing a number of properties that really do follow necessarily from it (i.e., from the very essence of the thing); and ... it infers more properties the more the definition of the thing expresses reality, i.e., the more reality the essence of the defined thing involves an intellect [ex data cujuscunque rei definitione plures proprietates intellectus concludit, quae revera ex adem (hoc est ipsa rei essentia) necessario sequuntur et eo plures quo plus realitatis rei definitio exprimit hoc est quo plus realitatis rei definitae essentia involvit] (E1p16d). ${ }^{42}$

However, Spinoza never defends this principle, and it not obvious how to go about such a defense, especially if the principle is supposed to justify the existence of modes. ${ }^{43}$ For why should a thing's infinite degree of reality require an infinity of non-essential properties? And if we wish to use this principle to justify the existence of finite modes specifically, we face an additional complication. For according to Spinoza finite things are essentially negations or limitations of substantial reality under a certain attribute (E1def2). Again, why should an infinite degree of a thing's reality require the production of such limitations?

In short, the argument Spinoza presents in E1p16d for the necessity of modes seems to be in need of nontrivial supplementation, if we are not to conclude that the principle on which it rests is itself just a piece of metaphysical dogma. A reader interested in rebutting the Idealists and justifying

Some of the discussion in this and the next paragraph appears in a footnote in Hübner forthcoming-b.

It is worth emphasizing here that E1p16 bears on all modes, not merely on finite ones, as is often assumed (see e.g. Melamed, 2010a:83, Viljanen 2011:22).

I assume that how many properties "intellect" can infer from a definition is supposed to be here a function solely of the essence's actual degree of reality, which the intellect grasps veridically, not of this intellect's abilities. (Cf. Spinoza's reference to an "intellect" in the definition of attribute.) Thanks to Clinton Tolley for discussion.

To my knowledge, this principle is without precedent in medieval literature; it is also absent from Descartes's work. However, it reappears in Leibniz, in the May $18^{\text {th }} 1715$ letter to Wolff (G 232). (Thanks to Marleen Rozemond and Martin Pickavé for help in establishing this.)

At first blush it may seem at least plausible to think that in Spinoza's framework the principle holds self-evidently in relation to substance's essential properties. (I.e., it may seem plausible to think that a thing's degree of metaphysical reality would be proportional to the number of attributes that constitute it, such that ceteris paribus a thing that is both extended and thinking would have a greater degree of reality than a thing that is merely extended, even if to an infinite degree [cf. E1p9d; Newlands 2011b].) But even here the situation is not so clear-cut. For traditionally God was often regarded as both maximally real and perfectly simple, that is, as possessing in himself no distinct properties or parts. So it does not seem to be self-evident that an infinite degree of reality must translate into infinite essential properties. (Thanks to Marleen Rozemond for discussion.) 
the necessity of modes must therefore either fill in the missing argument or construct an entirely different one. The argument I offer in $\S 4$ is one way of pursuing the second alternative. ${ }^{44}$

\section{2.}

The situation is not much better when it comes to Spinoza's official case for the necessity of substance being a thinking thing, which is the second claim I am interested in establishing in the paper. To be clear, given Spinoza's essentialist belief that all things have at least some essential properties, and given what he understands by "attribute" - at bottom, essential nature of substance-Spinozistic substance must have some attribute. That is, on pain of giving up on Spinoza's essentialism, at least one attribute must be given, if substance is given, for without an attribute there would be no substantial essence. ${ }^{45}$ Even without appealing to Spinoza's essentialism, we can plausibly claim on Spinoza's behalf that any "thing", including substance, must have some quality or property: substance cannot exist just qua substance, without any qualities whatsoever. ${ }^{46}$ It is, however, a separate question, why must it be thinking or extended in particular?

In the Ethics Spinoza himself offers two different arguments for the proposition "Thought is an attribute of God, or [sive] God is a thinking thing" (E2p1), adding that the claim "Extension is an attribute of God, or God is an extended thing" is demonstrable "in the same way" (E2p2d). ${ }^{47}$ The first argument is as follows:

44 See footnote 66 for discussion of some possible supplementations of E1p16d.

Could we argue that there must be modes because modes under an attribute are just determinates under a determinable, and it would be absurd for substance not to be determined in some way? (Thanks to James van Cleve for a suggestion along these lines.) This argument also will not work in Spinoza's framework because to think of substance as a 'determinable' is to assume that what is ontologically fundamental can be characterized as essentially a certain potentiality, one that becomes fully actual only through modes. This seems to invert the order of ontological priority that Spinoza establishes, making substance dependent on modes.

Since an attribute is more precisely what is "perceived" by an intellect to "constitute" the essence of substance, fully defending the necessity of attributes as Spinoza understands them would require more work than I can undertake here.

I will also not be able to address in this paper Spinoza's alleged failure to demonstrate the necessity of multiple attributes; for a recent defense see Della Rocca 2006. (It may go without saying that we cannot appeal here to the Principle of Plenitude and insist that substance must have maximally many attributes, if this principle is understood teleologically. Spinoza rejects metaphysical teleology at the level of substance-see E1app [II/ 77-80]; E4pref [II/206]. On Spinoza's use of the Principle of Plenitude see Newlands 2010.)

46 Cf. "nothing in nature is clearer than that each being must be conceived under some attribute" (E1p10s; II/52); "nothing has no properties" (Ep.13; IV/65). 
Singular thoughts, or this or that thought [Singulares cogitationes sive haec et illa cogitatio], are modes that express God's nature in a certain and determinate way (by $1 \mathrm{p} 25 \mathrm{c}$ ). Therefore (by 1def5) there belongs to God an attribute whose concept all singular thoughts involve, and through which they are also conceived. Therefore, Thought is one of God's infinite attributes, which expresses an eternal and infinite essence of God (see 1def6), or God is a thinking thing, q.e.d (E2p1d).

This first argument turns, explicitly, on Spinoza's version of a substancemode ontology and, implicitly, also on his conception of intelligibility. It starts with the empirically known existence of a finite or "singular" mode of thought. ${ }^{48}$ According to the PSR, everything is intelligible. But, to be intelligible, a mode of thought by definition requires the concept of another thing through which it can be made intelligible (E1def5). However, the entity doing this explanatory work must be causally related in the right way to the singular thought in question $(\mathrm{E} 1 \mathrm{ax} 4)$ - it must be a cause of the mode-and it must be of the same attribute-kind (E2p5-6). Moreover, it cannot itself require further explanation by reference to something else, since this would generate an infinite explanatory regress. ${ }^{49}$ So the explanans must be conceptually self-sufficient, i.e. a substance (E1def3), and furthermore a substance endowed with the relevant kind of nature. Putting all these requirements together, Spinoza concludes that what the existence of a singular thought requires is a thinking substance.

Spinoza's second argument for substance being res cogitans is laid out in the scholium that follows. It is an argument from conceivability:

This Proposition [God is a thinking thing] is also evident from the fact that we can conceive an infinite thinking being [possumus ens cogitans infinitum concipere]. For the more things [plura] a thinking being can think, the more reality, or perfection, we conceive it to contain. Therefore, a being that can think infinitely many things in infinitely many ways is necessarily infinite in its power of thinking. So since we can conceive an infinite Being by attending to thought alone [ad solam cogitationem attendendo

For the equivalence of "finite" and "singular" see E1p28. I assume that the singular thoughts are known empirically since the argument is supposed to apply equally to bodies.

If the series of reasons for a mode did not terminate in a self-causing substance and instead continued infinitely, then E2p1d could not establish the existence of a thinking substance as it is supposed to. See also e.g. TIE[30]; and Curley 1969:117. Spinoza's formulations of the PSR (E1ax2, E1p11altd) allow for an infinite series of reasons (all they require is a cause or reason for each thing); Spinoza also allows for an infinite series of determinations within Natura naturata (E1p28, E5p40s; cf. E1p32, E2p43). In Ep.12 (IV/61) Spinoza suggests that the problem with regresses is not their infinity as such but the fact that they imply that externally caused things do not require a self-causing thing. 
Ens infinitum concipiamus], Thought (by 1def4 and [1]def6) is necessarily one of God's infinite attributes, as we maintained (E2p1s). ${ }^{50}$

The above argument assumes Spinoza's definition of God as the being to whom all possible infinite natures actually belong: "whatever expresses essence ...pertains to its essence" (E1def6expl). The thrust of the argument is this: since we can conceive an infinite thinking being, and since by definition all such infinite natures belong to God, this infinite thinking nature must also belong to God.

This second argument is not without its problems. In the first place, one might have doubts that we can in fact conceive of something infinite, and especially that we can attain to such a conception simply by thinking of "more [plura]" things. One might also have more general doubts about what arguments from conceivability as such can show. ${ }^{51}$ A less controversial weakness of the second argument is that it simply fails to show that the infinite thing we are allegedly conceiving is an infinite substance, and not merely an infinite mode. (Spinoza himself seems to recognize this, in speaking of an infinite "being [ens]", not of an infinite "substance".) ${ }^{52}$

In the next proposition Spinoza states that we can run analogous arguments for extension. In other words, we can show, he thinks, that substance must be res extensa because (i) it must be possible to make singular bodies intelligible; and because (ii) we can conceive of an infinite extended thing. Here again we might have doubts: first of all, with Descartes, we may be skeptical that extension can be genuinely "infinite", not merely indefinite. ${ }^{53}$ More importantly, using Spinoza's two arguments to show that substance is an extended thing seems to contradict his commitment to the attribute-barrier. This is because both of the arguments appeal to truths about thought-truths about explanation or intelligibility (in the first argument) and about our cognitive capacities (in the second argument). ${ }^{54}$ However, the attribute-barrier demands that extended things be explained by reference to facts about extension alone.

\footnotetext{
$50 \quad$ Cf. also E1p35.

51 See e.g. the discussions in Gendler and Hawthorne 2002.

52 Della Rocca charges Spinoza's arguments with failing to block the possibility that thought would be explained by extension (1996:16). However, it seems likely that Spinoza thought that it self-evident that "thought" and "extension" are so heterogeneous as concepts that they could not explain one another. (We may of course disagree that this is the proper analysis of these concepts.) For further criticisms of E2p1s see e.g. Barker 1938:172.

53 See $\operatorname{Pr} .1 .26$. More generally Spinoza conceives of extension rather differently than Descartes (see e.g. Ep.83). 
Let me make one final point about Spinoza's two demonstrations. His claim that his arguments for substance being a thinking thing can also be applied to show that substance is extended is in fact an understatement: the form of these arguments is such that they can be applied to any attribute that might become cognitively available to us. I emphasize this because this universality of Spinoza's two arguments - their indifferent application to all attributes - obscures an important difference in the ways that different attributes in fact relate to Spinozistic substance, as we shall see in $\S 4$. More precisely, what is obscured by Spinoza's official arguments is thought's unique, ontologically fundamental relation to substance (and hence to being as such). Also for this reason then, as well as because of the difficulties mentioned above, Spinoza's official demonstration of the necessity of substance being a thinking thing leaves room for other kinds of arguments.

\section{3.}

Spinoza's own arguments for the claim that substance is a thinking thing suffer then from certain weaknesses. Spinoza's commentators do not, unfortunately, have much more to say on the subject of the necessity of thought as an attribute. Indeed, as already noted, apart from the Idealists, the question of why Spinozistic substance must have attributes generally, or this or that attribute in particular, is not raised very often. ${ }^{55}$ But two main arguments have been offered; I now turn to these. ${ }^{56}$

\subsection{1.}

Call the first argument the Argument from Possibles. The thought behind this argument is this: once we grant that thought (or extension) is a possible kind of being, there is no possible reason within Spinoza's metaphysics why substance would lack this kind of being. This is because there are no causal relations that could do the work: in a substance-monistic framework by definition there are no causes external to the substance that could prevent it from having an attribute; and, given the attribute-barrier, one attribute cannot prevent substance from possessing any other attribute. (So for example the fact that substance is extended cannot be a reason for it not being thinking.) As a result, as Della Rocca puts it, "each possible attribute necessarily exists". 57 On this account then, substance must be a thinking

\footnotetext{
55 We may speculate about possible reasons for this disinterest: the empirical obviousness of thought's and extension's actual existence; the logical indubitability of thinking, emphasized by Descartes; the difficulty of coherently articulating a scenario on which thought does not exist, emphasized by Berkeley; the general disrepute into which Idealism fell in the anglophone world post-Russell. 2012:258.
} 
thing just because it must have all possible attributes, including thoughtnot insofar as thought is thought specifically but insofar as it is an attribute. As was the case with Spinoza's two official arguments in E2p1d\&s, we can run an analogous argument for extension, and indeed for any other attribute.

Despite its relative popularity in literature, the argument, at least in its extant versions, suffers from the following flaw. It is true that, given Spinoza's commitments to substance-monism and to the attribute-barrier, once we assume that a certain attribute is possible, nothing can prevent its instantiation. The problem is that it is not clear that we are entitled to such an assumption within Spinoza's framework. Spinoza does not allow for intrinsic possibles, or any realm of logical truths that could in any sense exist independently of substance. In his view anything that is genuinely metaphysically possible is just a necessary effect and implication of substantial essence. (As Spinoza himself puts it, "everything which can fall under an infinite intellect [omnia quae sub intellectum infinitum cadere possunt]"-i.e., everything intelligible- "follows" "[f]rom the necessity of the divine nature" (E1p16). $)^{58}$ But if Spinoza does not recognize intrinsically possible kinds of being, then in order to be able to argue from the possibility of an attribute to its necessary existence, as the Argument from Possibles does, we first have to show why a particular substantial nature must be possible in Spinoza's framework. ${ }^{59}$ To be sure, we cannot coherently deny the possibility of thought in all its manifestations. But we can consistently deny the possibility that thought could constitute a substantial nature-i.e. the irreducible essence of a self-sufficient thing, and even that thought could be infinite (as opposed to, for example, merely indefinite). In short, the flaw in the extant versions of the Argument from Possibles is that they do not show that we have the right to consider thought as an attribute a possible in Spinoza's metaphysics. (Here Spinoza's own argument from conceivability, in E1p2s, proves superior in this one respect.)

A clarification is in order here. It is true that Spinoza does allow for merely possible modes. This is arguably at least part of what he has in mind when he notes that

5

2002:27.

58 Cf. E1p25: substance is the "efficient cause" of things' "essences". Potentially both E1p6 and E1p25 could be accommodated within a framework on which God merely recognizes and gives being to pre-existent eternal truths, but to my knowledge there is no textual evidence for attributing such a view to Spinoza.

On the nature of the "following" relation, see note 13. sion.) 
we can have true ideas of modifications which do not exist [modificationum non existentium veras ideas]; for though they do not actually exist outside the intellect [extra intellectum], nevertheless their essences are comprehended in another [in alio comprehenditur] in such a way that they can be conceived through it $(\mathrm{E} 1 \mathrm{p} 8 \mathrm{~s} 2 ; \mathrm{II} / 50)^{60}$

According to Spinoza, we can have true ideas of non-existent, merely possible, modes if we can construct ideas of such modes on the basis of ideas of what does exist. That is, we can make veridical claims about merely possible modes if these are (to use a Leibnizian phrase) "well-founded" beings of reason, mind-dependent entities grounded in ideas of what is in fact the case. ${ }^{61}$ But even if in this sense Spinoza admits mere possibles within his metaphysics, the above account cannot help us explain in what sense there could be merely possible attributes or substantial natures, which is what the Argument from Possibles requires. This is because a substance as we know is by definition conceived "through itself". Its attributes, or essential natures, presumably share this property of conceptual independence. For it seems implausible that substance would be essentially conceived per se but what "constitutes its essence" would not be so conceived. ${ }^{62}$ Indeed, this is precisely how Spinoza argues for E1p10, the claim that constitutes the core of the attribute-barrier doctrine: "each attribute...must be conceived through itself...[f]or an attribute is what the intellect perceives concerning a substance, as constituting its essence" $(\mathrm{E} 1 \mathrm{p} 10 \& \mathrm{~d})$. If we tried to use the reasoning Spinoza employs in E1p8s2 to show that we could have true ideas also of merely possible attributes, we would have to conceive of such attributes through ideas of other, existing things. (For example, we would negate the idea of an extended substance to arrive at the idea of a thinking substance.) But this way of conceiving of an attribute contradicts its conceptual self-sufficiency. Indeed, Spinoza himself explicitly restricts his reasoning in E1p8s2 to modes. ${ }^{63}$ To quote the passage in full,

we can have true ideas of modifications which do not exist; for though they do not actually exist outside the intellect, nevertheless their essences are comprehended in another in such a way that they can be conceived through it. But the truth of substances [substantiarum] is not outside the intellect unless it is in them themselves, because they are conceived through themselves (E1p8s2; II/50)

\footnotetext{
60 Cf. Newlands 2013:3.

61 For a more detailed account of Spinozistic entia rationis see Hübner forthcoming-c.

62 As is well known, Spinoza often simply identifies substance and attributes (see e.g. E1p4d; Ep.9 [IV/46]).

63

This makes his appeal to explanation and conceivability in E2p2d all the more baffling.
} 


\subsection{2.}

In short, the fact that Spinoza allows for true ideas of merely possibles modes does not establish the validity of thinking of attributes as mere possibles, as required by the Argument from Possibles. ${ }^{64}$ However, there is a flip side to this way of objecting to the Argument from Possibles. Namely, if attributes really do share in substance's conceptual self-sufficiency, as argued above, the existence of any attribute, including the attribute of thought, ought be seen as self-explanatory, just as the existence of substance itself is. That is, to the extent that we are able to make sense of the idea of substance being essentially in se and conceived per se, there is no additional problem created by the existence of the attributes. For when we talk about the attributes we are just talking about substance under a certain aspect, and substance qua extended and qua thinking is just as self-sufficient, conceptually and ontologically, as substance simpliciter. The Idealists' search for some deeper explanation of the necessity of attributes generally, or of the attribute of thought or extension in particular, is thus fundamentally misguided.

This is the second kind of argument for the necessity of attributes to be found in literature. ${ }^{65}$ Call it the No Genuine Problem Argument. The downside of this argument is that it does not fully address the charge made by the Idealists. One way to put the relevant part of this charge is to say, 'Why must God's "absolute infinity" entail these specific kinds of being, extension and thought?' (Recall Hegel's question: Why must there be thought and extension in particular?) It is true, as the proponents of this second Argument insist, and as I argued in my objection to the first Argument, that attributes are conceptually and ontologically self-sufficient, just like the substance whose essence(s) they constitute. This means that the existence of substance qua thinking (or qua extended), just like its existence qua substance simpliciter, is entailed by its essence, in a manner familiar from traditional ontological arguments for divine existence. But substance's being thinking or extended plays no role here: the precise quidditative nature of substance, so to speak, is irrelevant to its self-sufficiency. The No Genuine Problem Argument claims, at bottom, that in a Spinozistic context the question, 'Why does thinking substance exist?', is reducible to the question, 'Why does substance exist?'. But the problem with this argument is that it cannot account for the difference between a world in which God's "absolute infinity" consists only in being an infinite thinking thing, and a world in

\footnotetext{
64 Neither, it should go without saying, does it help to look to the epistemic sense of "possibility" which Spinoza reduces to our ignorance of what is in fact the case (E4def4). 
which this "absolute infinity" consists in being an infinite extended thing as well as an infinite thinking thing. The Idealist wants Spinoza to explain, in short, why God's "absolute infinity" takes on one form rather than another. And I agree that there is a genuine metaphysical fact here in search of an explanation. I conclude therefore that also the No Genuine Problem Argument fails to offer a satisfactory account of the necessity of Spinozistic substance being a thinking thing. ${ }^{66}$

\section{An Alternative Proposal}

Let me propose a different argument for the claim that Spinozistic substance must be both modified and thinking. More precisely, my goal in this section is to show that Spinozistic substance has these two properties necessarily, as a consequence of its essential nature as articulated in its definition, and that this can be demonstrated apriori, once we grant three of Spinoza's most basic metaphysical doctrines: to a substance-attribute-mode ontology; to a certain conception of intelligibility (understood to include a commitment

There are analogous arguments one could make for the necessity of modes. First, one could try to supplement Spinoza's argument in E1p16d by saying that the absolutely infinite reality of substance requires the existence of all possible non-essential properties (i.e. modes) because all "reality" is intrinsically conceived (suppressed premise) and modes are just partial ways of conceiving of being. (Cf. Newlands 2010 for this reading of modes.) The problem with this proposal is that like the Argument from Possibles it does not explain why partial ways of perceiving should be possible in the first place. (We cannot reason teleologically from the Principle of Plenitude; see note 45.)

Secondly, we could try to claim that modes must exist just because they are implicit in the nature of substance, and to that extent partake in substance's self-explanatory nature. But as long as we cannot say anything more about the kind of self-evidence that is at work here, this solution seems to be only verbally different from acknowledging that the existence of modes is a brute fact-precisely as the Idealists allege. (In contrast we can arguably say something more about the sense in which substance's own existence may be self-evident for Spinoza: namely insofar as existence is a property contained in substance's essence.)

Melamed proposes that Spinoza's Idealist critics can be answered by saying that "God's absolute infinity requires the instantiation of modes" (2013:72n54; emphasis in the original). This also seems to assume, in a question-begging way, that modes are somehow already (perhaps intrinsically) possible. (The argument would then be: modes must be instantiated or actualized, given the absolute infinity, or unlimitedness, of substance, which dictates that everything possible must be produced by substance.) As already noted, an Idealist would presumably demand to know why anything besides God should be possible in the first place. The same problem plagues Melamed's suggestion that E1p16d successfully answers the Idealist charge insofar as in that demonstration Spinoza "derives modes from the essence of substance as substance's propria" (2013:72, cf. 2010a). To truly answer the Idealists we would have to explain why propria should be possible, i.e. why substance must have propria in the first place (and not, for example, only essential properties). Finally, this same criticism could be lodged at the proposal there must be modes because substance must "act" in certain ways (see E2p3s and Deleuze, 1968/1990). The question once again is, Why cannot substance's sole action and actuality be its own existence under some attribute? 
both to the PSR and to the attribute-barrier); and to necessitarianism $\mathrm{i}_{\mathrm{i}}$. (As we saw above, Spinoza's own demonstrations of the necessity of specific attributes draw on the first two of these doctrines.) I hope that my account can illuminate aspects of Spinoza's metaphysical picture that arguments surveyed in the previous section have obscured, while circumventing their weaknesses. In particular, in contrast to arguments canvassed above, on my account the necessity of substance being a thinking thing will not follow from any feature common to all attributes, thereby obscuring thought's unique and ontologically fundamental relation to substancehood as Spinoza conceives of it.

\section{1.}

I will start by establishing that, for Spinoza,

(i) If substance exists, a mode exists necessarily.

Spinoza of course holds that the antecedent is necessarily true (E1p7), but for our purposes it suffices to prove the weaker, conditional form of the claim.

I take it to be fairly uncontroversial that Spinoza's commitment to the PSR allows us to establish apriori that if there is a mode, there must also be substance of an appropriate kind. This is because only such a substance can explain this mode without generating an infinite explanatory regress. (This line of reasoning was in play, we can recall, in Spinoza's first argument for substance being a thinking thing, in E2p1d.) My goal now is to show that the converse conclusion, though less obvious, holds equally: namely, that within Spinoza's framework it is equally possible to determine apriori that, if there is substance, there must also be a mode.

The premise that plays a key role in this argument is Spinoza's necessitarianism $\mathrm{i}_{\mathrm{i}}$, i.e., his necessitarianism about the infinite features of nature. Since substance in Spinoza's view is necessarily infinite (E1p8), it falls

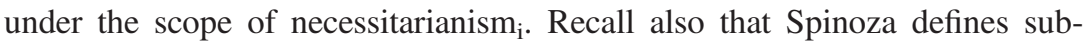
stance inter alia in terms of how it is "conceived", namely as something that is "conceived through itself" (E1def3). Now, given necessitarianism, if Spinozistic substance is a thing essentially "conceived" in a certain way (namely, without the help of other concepts), there must actually be a conception, or idea, of this substance. This is because necessitarianism $\mathrm{m}_{\mathrm{i}}$ dictates that nothing that pertains to infinite features of nature can remain merely possible or unactualized. So if it is truly the essence of substance - a necessarily infinite thing - to be conceived in a certain way, then this essential feature of substance must in fact be realized: there must actually be an appropriate conception of substance. Otherwise we have to conclude that Spinoza was wrong either about his definition of substance or about his 
necessitarianism $_{\mathrm{i}}$ (or indeed about both). Finally, given Spinoza's substancemode ontology, and, more precisely, given his belief that substances and modes are the only metaphysically possible entities, this necessarily existing conception of substance can only be a mode. In short, given even a limited form of necessitarianism, necessitarianism ${ }_{i}$, we can show that it follows from the definitions of substance and mode that if there is substance, there must also be a mode, i.e. some entity modally distinct from substance. ${ }^{67}$

The proposed argument goes through even if we opt for a weaker reading of the definition of substance, on which this definition asserts not that substance is conceived in a certain manner (as Spinoza's choice of a present passive indicative form of the verb in E1def3 suggests), but merely that it is so conceivable. On this weaker gloss of the definition, we would take the claim that substance is essentially "per se concipitur" to mean only that it pertains to substance to be explicable or intelligible in a certain way, or, to put it slightly differently, as the conditional claim that if substance were to be conceived by some thinking thing, it would be conceived without the aid of the concept of any other thing. Even if we read the definition in this way, we still arrive at the same conclusion, namely at the necessity of the actual existence of a mode of thought representing substance. This is because Spinoza's necessitarianism ${ }_{i}$ requires, as we have seen, that all genuine metaphysical possibilities pertaining to the infinite features of nature be actual. That is to say, if substance were not actually conceived-if there was no actually existing mode of thought representing substance-then it would not even be genuinely metaphysically possible for it to be so conceived. So it would not even be true to say that substance has the property of being per se conceivable or intelligible, as on the proposed weaker gloss of E1def3. As Spinoza writes, "Whatever we conceive to be in God's power, necessarily exists" (E1p35). Indeed Spinoza himself uses this proposition to move from the mere possibility of an idea representing substance's essence to the necessary existence of this idea:

God (by [2]p1) can [potest] think infinitely many things in infinitely many modes, or (what is the same, by 1p16) can form the idea of his essence and of all the things which necessarily follow from it. But whatever is in God's power necessarily exists (by 1p35); therefore, there is necessarily such an idea (E2p3d). ${ }^{68}$

An analogous argument cannot be made on the basis of the second half of E1def3.That is, we cannot infer the necessary existence of a mode from the fact that a substance is "in itself". This part of the definition does not imply any self-modification by substance. However, if we also grant that there are other attributes besides thought, and that modes under different attributes are numerically identical (E2p7s), then we could also establish apriori the necessary existence of a mode of extension identical to this mode of thought. 
In short, whether we opt for a modally stronger or weaker gloss of Spinoza's definition of substance, either way we arrive at the same conclusion: a mode of thought representing substance exists necessarily if substance itself exists.

Can we say here anything more about the mode of thought whose necessary existence we have just proved? In particular, the above argument seems to leave undetermined whether this mode is finite or infinite. That is, the conception of substance necessitated by Spinoza's definition of substance, in combination with his necessitarianism ${ }_{i}$, might, it seems, equally well be a finite idea formed by some "mind", or it could be an infinite mode of thought. In fact, however, this appearance of indeterminacy is just an appearance. Once we take into account how Spinoza conceives of the relation between infinite and finite modes of thought it quickly becomes apparent that we have established the necessity of an infinite mode of thought alone. This is because in Spinoza's view a finite mode of thought cannot exist without an infinite one: any finite "mind" is merely a "part [pars]" of substance's "infinite idea" (E2p11c, cf. E5p40s). ${ }^{69}$ Hence whether the conception necessitated by substance's definition is finite or infinite, an infinite mode of thought must exist.

\section{2.}

So far then we have established that for Spinoza

(i) If substance exists, a mode exists necessarily;

and more specifically that

(i') If substance exists, an infinite mode of thought exists necessarily.

By establishing (i), we have shown that, contrary to the Idealist charge, Spinoza's metaphysics does have the conceptual resources to demonstrate the necessity of at least one sort of ontological diversity in nature: the diversity that comes from the existence of things modally distinct from substance.

69 In E2p11c it is the "human" mind that is described as a "part" of the infinite intellect, but I take it that the point generalizes to non-human minds (cf. E2p13s).

Finite minds are contained within the infinite idea for the most part indiscernibly, becoming discernible only when the bodies they essentially represent begin to exist durationally (E2p8c\&s, E2p11,13). So the infinite idea is not a whole composed out of finite minds, where the component parts would be prior.

The conclusion that the mode in thought in question is infinite is arguably further supported by the fact that this mode appears to be an immediate consequence of the essential nature of substance itself (cf. E1p21-2), specifically of substance's having the essential property of being "conceived per se". 
On the basis of (i'), we can go on to refute a further part of that charge, by showing that Spinoza's metaphysics also has the resources to prove the necessity of a specific kind of being: thought. For from (i') it is relatively straightforward to show that

(ii) A thinking substance must exist.

This is the second claim I want to establish in this paper. (ii) follows, along the lines of Spinoza's own argument in E2p1d, from Spinoza's definition of mode together with his conception of intelligibility. For, given these premises, the infinite mode of thought necessitated, as we just saw, by the definition of substance in combination with Spinoza's necessitarianism ${ }_{\mathrm{i}}$, requires the existence of a substance of the same attribute-kind and appropriately causally related to the mode. I.e., the existence of this mode of thought implies the existence of a self-sufficient thinking thing, capable of furnishing an explanation of its existence and nature without engendering an infinite regress of explanations.

In a substance-monistic framework like Spinoza's, this conclusion that a thinking substance must exist has of course a different meaning than in a substance-pluralistic one. ${ }^{70}$ For in a substance-monistic framework there is only one substance that can be the thinking substance in question, providing the needed explanatory grounding for the infinite mode of thought representing substance. There is simply no other substance to do the job. Hence within Spinoza's framework the only possible substance must be a thinking substance, or, there cannot be a substance that is not a thinking thing.

In short, we can conclude that for Spinoza

(ii') Substance is necessarily a thinking thing.

I take this to show that, according to Spinoza, thinking is inseparable from substancehood as such, i.e., from the most fundamental way of having being. For this reason I believe that in Spinoza's metaphysics thought deserves to be seen as an ontologically fundamental kind of being, where 'fundamentality' denotes inseparability from the most basic way of being.

For the purposes of this paper I will treat substance-monism as part of Spinoza's conception of the nature of substance. This is a plausible reading, given the essential existential and conceptual self-sufficiency of every "substance", which implies that every purported substance other than God is in Spinoza's view in fact internally inconsistent. Spinoza's official demonstration of substance-monism relies on the definition of God and on the impossibility of attribute sharing among numerically distinct substances. The nature (and success) of Spinoza's argument there is a matter of controversy. Given limited space, I cannot enter into this discussion here, but see references in note 4 . I also cannot examine here Spinoza's claim that God's nature is consistent (he claims that this follows from his "absolute infinity" and "supreme perfection" [E1p11d]. 
Spinoza's substance-monism has also the following ramifications. Namely, substance-monism dictates that substance is not merely necessarily thinking but also that

(iii) Substance must be modified

or, more precisely, that substance must modify, or determine, itself. This follows, given substance-monism, from (i), which, to recall, states that if substance exists, a mode must also exist. For if a mode must exist and if (by substance-monism) there can be only one one thing that could provide the requisite ontological and conceptual grounding for this mode, then the only possible substance must be modified. In this sense for Spinoza the notion of a "bare"- - unmodified or undetermined - substance turns out to be a metaphysical impossibility.

Putting all the claims we have established together, we can conclude that according to Spinoza (a) the only possible substance must be actually conceived by some actually existing infinite mode of thought; (b) this substance must be thinking, i.e. a res cogitans; and (c) this substance must modify or determine itself by means of the aforementioned infinite mode of thought (by its own conception of itself), i.e., as a thinking thing it must give rise to this particular idea. Conversely (and utilizing admittedly nonSpinozistic vocabulary), the infinite mode of thought in question-i.e. the conception of substance required by its definition - is both (a) a representation whose intentional object is this substance, and (b) a representing done by this substance. That is, the idea of substance both has substance as its represented object and also is had by the substance as the conceiving "subject".

\section{Clarifications and Objections}

In the previous section I presented an argument for the conclusion that Spinozistic substance is necessarily, as a consequence of its essential nature, and in apriori demonstrable fashion from the very definition of substance, both modified and thinking. In this section I want to offer some clarifications, and address a couple of potential objections to my account.

\section{1.}

I will start with the clarifications.

First, the conclusion that Spinozistic substance must be a thinking thing clearly does not mean that it cannot also be other kinds of thing (for example, extended). So my argument is consistent with Spinoza's commitment to a plurality of attributes (E1def6; E2p1-2; E2p7s [II/90]). All I have shown is that whatever else Spinozistic substance turns out to be, it must, minimally, be a res cogitans. (In other words, the "absolute infinity" of the 
only possible substance must at the very least include thought as a kind of being.)

Secondly, unlike the arguments Spinoza himself gives in E2p1d\&s, and unlike the two arguments found in secondary literature, my argument for the claim that substance is necessarily a thinking thing does not work indifferently for every attribute. My argument shows that for Spinoza thought is inseparable from substancehood as such, but we cannot use it to establish the necessity of substance being an extended thing. This is not to suggest that extension for Spinoza is not just as necessary as thought, or that it does not fully "express" substance, ${ }^{71}$ only that for Spinoza its necessity does not seem to be tied to the very idea of substantiality. ${ }^{72}$ In other words, there appears to be nothing incoherent, prima facie at least, about a Spinozistic "substance" for which being extended simply would not be metaphysically possible. Of the two kinds of being that Spinoza takes to be humanly knowable - thought and extension - only thought seems to be inseparable from substance qua substance in this way. ${ }^{73}$

This inseparability of thought from the very idea of substancehood constitutes yet another way that Spinoza departs from the Cartesian conception of substance. The two thinkers' beliefs about what it is to be a "substance" differ not just because - as is often noted-Spinoza does not believe that there can be multiple substances, or finite ones. Their views on the nature of substance diverge also because Spinoza, unlike Descartes, holds that there cannot be a non-thinking substance-for example, a substance whose entire nature would consist exclusively in extension.

The final clarification I want to make is this. My account makes some headway towards answering Idealist criticisms of Spinoza's system: it

As Spinoza says, "all the attributes [substance] has have always been in it together, and ... each expresses the reality, or being of substance" (E1p10s).

Compare this to Spinoza's own distinction between different sources of metaphysical necessity: the internal necessity of substance's own being vs the external necessity of the existence of modes (E1p33s1).

We could try to argue that extension is necessary insofar as there can be no thought unless this thought has an object distinct in kind to represent (cf. E2p8c; E2p11; E2p13; but see E1p10). But even this argument does not tie the necessity of extension directly to the essential nature of substance - it only shows transitively that extension is necessary to thought and therefore to substance.

Would it be possible to derive the necessity of extension from the fact that the definition of substance describes substance as being "in se"? No, as that would necessitate conflating the 'in' of inherence (at stake in the definition) with the 'in' of spatial containment. (See Garrett 2002.) Thanks to Clinton Tolley for pressing me on this.

Another way to put this uniqueness of thought is this: Spinoza's epistemology assumes that all falsehood requires a positive cause, and that there is no possible cause of falsehood in relation to substance (E2p32-35). On my account, substance cannot misapprehend itself as a non-thinking kind of thing when it apprehends itself in its absolute infinity. But it seems in principle possible that it could conceive of itself solely as a thinking kind of thing. 
shows that such criticisms overlook how closely in Spinoza's framework the essential nature of substance is tied both to the existence of infinite modes and to the necessity of at least one kind of being (thought). But I readily admit that I have not fully answered the Idealist charge that Spinoza fails to demonstrate the necessity of ontological diversity. For one, I have not shown that Spinozistic substance must be endowed with the "attribute" of thought as Spinoza understands this technical term in all its detail. (For example, I have not established that substance's thinking must be understood specifically as "expressing" and "constituting" its essence.) Likewise, I have done nothing to show that Spinoza's system has the conceptual resources to establish the necessity of finite modes specifically. That said, it seems to me that we should not downplay to the significance of establishing the necessity of ontological diversity at the level of infinite modes. To do so would be out of step with Spinoza's own metaphysical priorities. That is, our own finitude should not blind us to the fact that within Spinoza's framework, to focus on the finite - as most Idealists and their critics do-is dangerously close to a form of anthropocentrism, against which Spinoza so frequently protests. ${ }^{74}$

\section{2.}

So much for the clarifications; let me now turn to some potential objections to my account. All three of them have that in common that they reject, for one reason or another, my interpretation of Spinoza's definition of substance.

\subsection{1.}

The first objection concerns my gloss of concipere in E1def3. In $§ 4.1$ I suggested that for our purposes there is no significant difference between glossing Spinoza's definition of substance as the claim that substance is actually conceived per se and glossing it as the claim that substance is merely conceivable per se. However, one could object that we should opt for an even weaker gloss of the definition, such that to assert that a substance is "per se concipitur" means only that certain conceptual relations are true of

74 See e.g. E1app (II/77-9); E2p3s. Hegel for one does not adequately distinguish finite and infinite modes in his account, often conflating "mode" with a "finite" thing (see e.g. 1995:260, 270.) Nonetheless, he recognizes the folly of excessive preoccupation with finitude, describing the critics of Spinoza's undifferentiated substance as unable to "forgive Spinoza for thus annihilating them.” (1995:281-2)

On Spinoza's alleged failure to justify the necessity of finite things specifically, see Caird 1888:123, 144; Hegel 1995:258, 281-8; Joachim 1901:44-5, 110-12; Martineau 1882:205, Pollock 1880:191. For discussion see Deleuze, 1968/1990; Hübner forthcoming-b; Macherey 1979; Melamed, 2010a, 2013; Newlands 2011b. On Spinoza's antianthropocentrism see Melamed 2010b. 
the idea of "substance", or that that this concept has a certain place in the relevant conceptual scheme, just as we might say, for example, that " $<$ Bachelor $>$ is conceived through $<$ male $>$ ", or " $<$ Human $>$ is conceived through $<$ animal $>$ ". Surely (the objection goes) we do not take such examples to imply that there is actually or even merely possibly some conceiver, engaged in mental acts. On this objection, in short, we must "de-animate", so to speak, Spinoza's terminology of "conception", distancing it from any kind of psychology, and associate it instead with something like a Fregean third realm. ${ }^{75}$

This is the objection; now let me say why it fails. There are to be sure good reasons, independently of the present context, why one might wish to distinguish Spinozistic "conception" from the kind of activity of thinking that a mind-or, more generally, a res $\operatorname{cogitans}^{76}$ - might engage in. (For example, on may worry that Spinoza's reliance on the terminology of "conception" in relation to every attribute, not just thought (E1def4; E2p6d; TTP 4 [III/60]), contradicts his commitment to the attribute-barrier.) ${ }^{77}$ Nonetheless, the move that the objector wants to make is simply not a move that can be made within Spinoza's framework. This is because for Spinoza all conceiving is indeed ultimately the activity of a thinking thing (at bottom, of a thinking substance). This is clear first of all on textual grounds. For example, Spinoza equates "conceiving" with "attending to [attendere]" something (E2p1s) and "forming [formare]" concepts (E1def3, E1p8s2 [II/ $50]$ ), both of which suggest mental activity. Likewise, he clarifies that he chose to define "idea" as a "concept of the Mind that the Mind forms because it is a thinking thing" because, unlike "perception", "[']concept['] seems to express an action of the Mind [conceptus actionem mentis exprimere videtur]" (E2def3\&expl). Consider also Spinoza's definition of attribute, one of the grounding claims of the Ethics: even here the "perception" of substance as essentially this way or that is made explicitly by an "intellect".

That it would be futile within Spinoza's framework to try to dissociate "conception" from mental activity (where 'mental' refers not just to minds but also to intellects) is further confirmed on purely conceptual grounds. For (to reiterate a point made earlier, in reference to the Argument from Possibles) how else could conceptual relations be grounded within Spinoza's framework if not in the way that substance thinks, given that Spi-

Thanks to James van Cleve and Alan Nelson for objections along these lines. See also the account of Spinozistic "conception" in Newlands 2012. For Frege, see 1967:15-16; 1968:viii.

There are reasons to think "minds", unlike "intellects", are for Spinoza always finite; see note 27 . 
noza does not allow for a logical realm existing independently of substance? As we have seen, given Spinoza's commitments to intelligibility, the truth of conceptual relations-such as those holding between $<$ bachelor $>$ and $<$ male $>$ - must not only be grounded in something, but ultimately (on pain of infinite regress) it must be grounded in substance as a thinking thing. In other words, the reason why these and all other conceptual relations hold is just the internal necessity of substance's own thinking.

So I think that Bennett was right to say that Spinoza "does ignore the difference between mental items and third-realm ones". ${ }^{78}$ And Spinoza is certainly not alone in the period in thinking in this way about the relation between conception generally and the activity of a perfect thinker. (Consider for example Malebranche's claim that we see all ideas "in God", or Leibniz's claim that even eternal truths depend for their being on the divine understanding. $^{79}$ To be clear, I do not wish to deny that Spinoza allows for uses of concipere where this term refers most immediately just to the abstract holding of certain relations between concepts. This may even be the most immediate sense in which concipere is used in the definition of substance: that definition can indeed be read as simply delineating certain conceptual relations between <substance $>$ and <conception>. But within Spinoza's framework this 'de-psychologized' sense of concipere is ultimately always only an abstraction and derivation from the fundamental Spinozistic meaning of "conception" as the activity of a thinking thing. It possible, and has meaning, only on that basis.

In short, within Spinoza's framework we cannot, except by abstraction, detach conceptual relations from a conceiver, or posit a third realm separate from a psychology. The mental activity of a thinking thing - the actual representing of a certain object in a certain way-is the condition of possibility of the relevant concepts ( $<$ being conceived per se $>$ and $<$ substance $>$ ) standing in a certain relation to one another. For Spinoza it is the psychology that is basic, with the caveat that the "psyche" in question is very different from what other "psychologist" frameworks might posit: it is the psyche of an infinite thinking substance.

\section{2 .2}

There is, however, another way one could object to my gloss of concipere in E1def3. Namely, one could insist that there could be conception of substance (let's say by substance itself) but no mode of thought. On this objection, substance could think itself simply by being the objective reality of itself: the conception of substance would be identical to substance

1984:52.

79 Thanks to Clinton Tolley for discussion. 
itself, such that there would be no difference between the thought of substance and substance. ${ }^{80}$ In this case, even if we grant that substance is necessarily actually conceived, and even that Spinozistic conception ultimately always requires the activity of a thinking thing, we still have no grounds on which to establish the necessity of a mode, and hence no grounds on which we demonstrate, contra the Idealist, the necessity of this kind of ontological diversity in Spinoza's metaphysics.

I believe that also this objection can be refuted. This is because textually it is fairly clear that in Spinoza's view all thinking, even thinking in which substance engages, requires the formation of ideas, such that there can be no objective reality and no conception unless there is also a formally-real mode of thought (which, as a mode, cannot be identical to substance itself). This understanding of conception as a formation of ideas is suggested for example by Spinoza's explaining God's "power of thinking [cogitandi potentia]" in terms of "ideas", as what "follows objectively in God from his idea [ex Dei idea...sequitur in Deo objective]" (E2p8). What "follows objectively from [an] idea" is presumably just other ideas, with their objective realities. Spinoza also equates substance's thinking with the forming of ideas in E2p3d:

God (by [2]p1 [="Thought is an attribute of God, or God is a thinking thing"]) can think infinitely many things in infinitely many modes, or (what is the same, by 1p16) can form the idea [cogitare sive (quod idem est...) ideam...formare potest] of his essence and of all the things which necessarily follow from it (E2p3d; emphasis added).

Finally, Spinoza repeatedly, systematically and explicitly identifies substantial "cognitio" and "ideas" by means of "sive" (see e.g. E2p20\&d, E2p21d25d, E5p23d). ${ }^{81}$

I conclude therefore that the second objection to my gloss of "conceived through itself" in E1def3 is textually untenable.

\subsection{3.}

A third possible objection to my reading of Spinoza's definition of substance is this. If my account is correct, and by Spinoza's own definition there indeed cannot be a "substance" without a mode of thought modifying it, this seems to render substance essentially dependent on another thing,

Thanks to Don Garrett and Bill Seager for objections along these lines. See also Garrett forthcoming, and Lewis 1986:145.

Cf. also: "Whatever happens in the singular object of any idea, there is cognition of it in God, only insofar as he has the idea of the same object [ejus datur in Deo cognitio quatenus tantum ejusdem objecti ideam habet]" (E2p9c; transl. alt.). However, since the scope of this quote bears only on God's cognition of objects of ideas, it is arguably consistent with the proposal that God can also know without forming ideas. 
thereby contradicting its definition. For substance is supposed to be an entity essentially conceived "through itself", one "whose concept does not require the concept of another thing" (E1def3). But (the objection goes), on my account, Spinoza's definition of substance effectively makes substance into something that does require the concept of "another thing"-of an infinite mode of thought - to be what it essentially is (i.e., to be as its definition represents it). In other words, on my account Spinoza's definition of substance both stipulates that substance is essentially conceptually independent from every other thing, and effectively makes substance depend on a mode of thought to be what it essentially is, i.e. independent. That is, my account seems to render Spinoza's definition of substance inconsistent and, in so doing, to undermine the very distinction between modes and substances that is fundamental to Spinoza's ontology, by making substance just as dependent as a mode. But if Spinoza's definition is really inconsistent in this way, then it cannot be a genuine "definition"- that is, it cannot capture the essence of a substance (or, for that matter, the essence of any thing).

The objector can freely concede here that in Spinoza's substance-monistic framework modes are not things "other" than substance in the same sense as another substance would be. For modes are not "really" distinct from substance. Nonetheless, she will (rightly) insist that Spinozistic modes deserve to be seen as something "other" than substance as much as anything can be an "other thing" in Spinoza's framework: namely, they are modally distinct from substance. (Indeed, unless we regard modes as "other" than substance in some significant and non-illusory sense, we are capitulating to the Idealist picture of Spinozistic substance as a completely undifferentiated "abyss", to borrow Hegel's rather dramatic imagery.) ${ }^{82}$ Spinoza himself clearly regards modes as "other" than substance in the relevant sense. For example, he describes substance as "prior in nature [prior...natura] to its affections" (E1p1). Such "priority in nature" presumably requires at least some distinction in the relevant "natures"; this in turn seems to suffice for modes to count as "other" than substance. On the basis of E1p1 Spinoza also asserts that if we wish to consider substance "truly", i.e. "in itself", we must "put affections to one side [deponere]" (E1p5d; II/48). This implies that no conception of substance that makes an ineliminable reference to modes can count as a conception of substance as it is "in itself". Again, this seems to confirm that a mode is a thing "other" than substance. From the objector's point of view, it also suggests that on my account Spinoza's definition of substance fails to be a "true" conception of substance as it "in itself", since on that account the definition does seem to make an ineliminable reference to a mode. In the words of E1p5d, on my account Spinoza's 
definition of substance fails to put modes "aside", violating Spinoza's own criterion of a true conception of substance as it is in itself.

There are several possible responses to this third objection. In the first place, one could conclude on its basis that my account of Spinoza's definition in $\S 4$ simply cannot be right. Or one might endorse both my account in $\S 4$ and the objection, and see Spinoza's definition as inconsistent. For how can it be consistent to claim that the essential nature of substance is to be "conceived" (E1def3), when every intellect and every idea is exiled by Spinoza outside substantial essence, into the world of modes (E1p17s[I] [II/ 62]; E1p31) $?^{83}$ Or, finally, one might grant the objection, but see it as a reason to endorse my account, insofar as it reveals the "deeper" metaphysical truth that, pace Spinoza, what is ontologically fundamental cannot after all be entirely self-sufficient. ${ }^{84}$

I don't think any of these responses is the right way to go. I think that we can defend the account proposed in $\S 4$, as well as the consistency of Spinoza's definition of substance, and that it is the objection that ought to be rejected. For the objection only gets off the ground if we are insufficiently careful when glossing the idea of being "conceived per se". What E1def3 says is that for something to count as conceived "through itself" its concept must not only not "require the concept of another thing", as noted in the objection, but, more specifically, that its concept cannot "require the concept of another thing, from which it must be formed [a quo formari debeat]" (E1def3, emphasis added). That is, according to Spinoza, for $x$ not to be conceived "through itself", the concept of $x$ has to be derived from ("formed from") the concept of $y$, where $x \neq y .{ }^{85}$ So, contrary to the objection, failure to be conceived "through itself" requires more than a mere inseparability of the concept of some "other thing" from the concept of $x$. Namely, it requires the concept of this other thing to function as a premise or ground in the formation of the concept of $x$. But the account outlined in $\$ 4$ does not require us to form the concept of substance from the concept of a mode. (Indeed, the direction of derivation was exactly the opposite: the existence, necessity, and representational content of this mode of thought was derived from substance's essential property of being "conceived through itself".) So, contrary to the objection, my account does not render

See also Barker 1938:173.

Cf. Hegel: "The only possible refutation of Spinozism must consist in the first place in recognizing its standpoint as essential and necessary, and then going on to raise that standpoint to the higher one through its own immanent dialectic. The relationship of substance considered simply and solely in its own intrinsic nature leads to its opposite. .." (1969:581; emphases added).

Cf. Della Rocca 2002:16. For how Spinoza might understand the nature of derivation at issue here see note 13 . 
the definition of substance inconsistent, by making it impossible for substance to be conceived per se.

It is true that on my account the concept of substance proves to be inseparable from - it proves to imply - the concept of a certain mode. But this is why earlier I stressed the importance of distinguishing within Spinoza's framework between what is essential to a thing, and what is merely necessary to it. On my account, the property of being conceived in a certain way ("per se") is an essential property of substance, and belongs to substance as it is "truly" and "in itself". But the resulting mode of thought-the conception of substance - is only a necessary consequence or implication of this essential property of substance. This inseparability of the concept of a mode of thought from the concept of substance is no different from the inseparability of propria from a thing's essence: propria follow necessarily from an essence, without thereby constituting a part of it, or belonging to its conception as it is in itself. ${ }^{86}$ This becomes even clearer if we consider Spinoza's substance not insofar as it is the definiendum of E1def3 - a certain abstract universal: "substance" in general ${ }^{87}$ — but insofar as it is the absolutely infinite God of E1p16, from whose essence "there must follow infinitely many things in infinitely many modes". Substance so conceived is inseparable from an infinity of modes in the same way that the general idea of substance, articulated in E1def3, is inseparable from the infinite mode of thought. Neither implication makes substance any less self-conceived.

I conclude therefore that the account in $\$ 4$ can be defended also against this last objection.

\section{Spinoza's Definitions}

Let me end the paper by drawing attention to one further consequence of my account of substance. The consequence I have in mind concerns the definitions that form the premises, so to speak, of Spinoza's deductively-structured Ethics. Namely, the account proposed in $\$ 4$ illustrates how deeply Spinoza's metaphysics is shaped by commitments explicit or implicit already in his definitions. ${ }^{88}$ For this reason, my account poses with particular urgency the question of how Spinoza might go about justifying these definitions. The problem is not particular to my account: it is also true of

86 Cf. "We require a concept, or definition, of the thing such that when it is considered alone. . all the thing's properties can be deduced from it. . That this is a necessary requirement of a definition is. . plain through itself" (TIE[96]; cf. E1p16d).

For Spinoza's warning against confusing propria and essences see TIE[95] (I/34). For analysis of Spinoza's ontology in terms of the Scholastic category of propria see e.g. Garrett 2002, Hübner 2015, Melamed 2009, 2013.

87 For a fuller defense of this reading of Spinoza's definitions and universals see Hübner forthcoming-c. 
Spinoza's own arguments in the Ethics (for example, of his arguments for substance being thinking and extended) that at key moments they appeal to his definitions. It is a worry that was raised already by Hegel: "the whole of Spinoza's philosophy is contained in these definitions", but the definitions themselves are "simply accepted and assumed, not deduced, nor proved to be necessary". ${ }^{89}$ Let me say a few quick words to flesh out this worry, and some of the ways it could be assuaged.

\section{1 .}

As is well known, Spinoza holds that good definitions capture the essences of their definienda, and in so doing disclose the "true" natures of their objects (Ep.4 [IV/13]; Ep.9 [IV/42-3]). ${ }^{90}$ It is not clear however, how as readers we are to know that (for example) the Ethics' definitions of substance and mode are indeed true, that is (by E1ax6), in "agreement" with their objects. Why, in particular, should we take substance to be essentially something "conceived through itself"? For it is this clause that generates the series of further commitments that we have been tracing here. Of course, formally, "definitions" are not "propositions". Formally, it would seem, it is the latter that require, and are amenable to, proper "demonstrations". 91 But Spinoza also often treats these formal labels as merely relative and extrinsic to what is being defined. ${ }^{92}$

One possible solution is to trace the problematic clause in the definition of substance to a prior commitment to the PSR, à la Della Rocca. Substance would then be essentially conceived through itself because all conception involves reference to a thing's causes (E1ax4), and substance's essential ontological self-sufficiency results in conceptual self-sufficiency. (This approach does not entirely solve our problem however, since we still have to justify Spinoza's commitment to substance being defined as in se.)

We may try to look for a solution also in Spinoza's suggestion that true ideas are intrinsically certain (E2p43s [II/124]; TIE[35-6]). Some have

1995:263, 283; cf. 260, 269, 285. Indeed, there are few Spinozistic doctrines that do not rely on his definitions.

Spinoza does not explicitly identify the non-nominal account of definition he outlines in these letters as an account of how he himself uses definitions. But this seems to be a plausible assumption.

Since Spinoza's definitions are supposed to be true, or in "agreement" with their objects - and not merely an arbitrary artifact of Spinoza's method-we do not have to worry that on my reading his method dictates the content of his philosophy. Rather, Spinoza's method (including the definitions) is an attempt to reproduce the intelligible structure of nature (including the essences that make it up). (Thanks to James van Cleve for this question.) 
argued on this basis that Spinoza's definitions are meant to be self-evident. ${ }^{93}$ On this approach we could perhaps argue that the problematic clause in E1def3 is self-evidently true because it is self-evident that what is ontologically fundamental must be conceivable without appealing to the concept of anything else.

We could also take solace from the fact that Spinoza undertakes to demonstrate that his definition of "God", E1def6, has an actually existing object (E1p11d). ${ }^{94}$ We can see this as an indirect demonstration that the definition of "substance", E1def3, also has a real object. Then the only remaining task would be to see how good the proof is.

One final interpretative option is to assume that Spinoza's definitions are justifiable retrospectively, by virtue of the explanatory power of the system the Spinoza is able to construct on their basis. ${ }^{95}$ (We could judge this for example by the extent to which Spinoza's fine-grained analyses of human emotions latch onto phenomena.)

This hypothetico-deductive approach is certainly encouraged by Spinoza's optimistic comment that

when the mind attends to a thought - to weigh it, and deduce from it, in good order, the things legitimately to be deduced from it - if it is false, the mind will uncover the falsity; but if it is true, the mind will continue successfully, without any interruption, to deduce true things from it. (TIE [104]).

However, it is not clear that deductive fecundity really does track truth in this way. Even if we grant the assumption that the whole of reality is intelligibly interconnected, why not think that what is not actually the case can be equally systematically interconnected, such that we can continue on deducing non-existent things "without interruption"? (Leibniz could be said to have thought so, given his ontology of possible worlds.)

\section{2.}

The preceding is not intended to be exhaustive: fully addressing the question of how Spinoza justifies his definitions would require separate treatment. My concern right now is only to stress that whatever answer we opt for, we must it seems opt for some answer, if we wish to defend Spinoza from the charge that his system unfolds from arbitrary premises, with little 
more to be said in their favor than that they have been sanctioned, to some degree, by tradition. ${ }^{96}$

On the reading of Spinoza I have been arguing for, Hegel's first worryhis worry about Spinoza's ability to demonstrate the necessity of ontological diversity - is in part at least reducible to this second worry, about how Spinoza might justify his choice of definitions. For if the account I presented is correct, the necessity of substance being a thinking thing and the necessity of it modifying itself both follow in part at least from Spinoza's choice of definitions. All the greater the need then to answer this second Hegelian question. ${ }^{97}$

\section{References}

Aristotle (1984). The Complete Works of Aristotle, ed. J. Barnes (Princeton).

Barker, H. (1938). Notes on the second part of Spinoza's Ethics, Mind 47:417-39.

Bayle, P. (1991). Historical and Critical Dictionary: Selections, tr. R. Popkin (Hackett).

Bennett, J. (1984). A Study of Spinoza's Ethics (Hackett).

Berkeley, G. (2009). Philosophical Writings, ed. D.M. Clarke (Cambridge).

Caird, J. (1888). Spinoza (Elibron Classics).

Carriero, J. (1995). On the relationship between mode and substance in Spinoza's metaphysics, Journal of the History of Philosophy 33:2, 24573.

(2002). Monism, in Spinoza, in Koistinen and Biro, 38-59.

Crane, J.K. and Sandler, R. (2005). Identity and distinction in Spinoza's Ethics, Pacific Philosophical Quarterly 86(2):188-200.

Curley, E. (1969). Spinoza's Metaphysics: An Essay in Interpretation (Harvard).

and Walski, G. (1999). Spinoza's Necessitarianism Reconsidered, in Gennaro and Huenemann, 241-62.

Deleuze, G. (1968/1990). Expressionism in Philosophy: Spinoza, tr. M. Joughin (Zone Books).

Della Rocca, M. (1996). Representation and the Mind-Body Problem (Oxford).

— (2002). Spinoza's Substance Monism, in Koistinen and Biro, 11-37. (2003a). Rationalist Manifesto: Spinoza and the Principle of Sufficient Reason, Philosophical Topics, 31:1/2, 75-94.

\footnotetext{
$96 \quad$ For this conclusion cf. e.g Barker 1938:160.

97 Thanks to Michael Della Rocca, Don Garrett, Alan Nelson, Bill Seager, Clinton Tolley, James van Cleve, and the participants of the 2013 Eastern APA for invaluable comments on earlier drafts of this paper.
} 
(2003b). Power of an idea: spinoza's critique of pure will, Noûs 37:2, 200-31.

- (2006). Explaining explanation and the multiplicity of attributes, eds.

M. Hampe and R. Schnepf, Baruch de Spinoza: Ethik (Akademie Verlag).

(2008). Spinoza (Routledge)

- ed. (forthcoming). The Oxford Handbook to Spinoza (Oxford).

Descartes, R. (1974-86). Oeuvres, ed. C. Adam and P. Tannery (Vrin/ CNRS).

- (1985). The Philosophical Writings of Descartes, 3 vols, eds. J. Cottingham, R. Stoothoff and D. Murdoch (Cambridge).

Donagan, A. (1973). Essence and the distinction of attributes in spinoza's metaphysics, in Grene, M., ed. Spinoza: A Collection of Critical Essays (Doubleday/Anchor), 164-81.

_ (1988). Spinoza (University of Chicago).

Duns Scotus, J. (1988). Philosophical Writings (Hackett).

Förster, E. and Melamed, Y., eds. (2012). Spinoza and German Idealism (Cambridge).

Franks, P. (2005). All or Nothing: Systematicity, Transcendental Arguments, and Skepticism in German Idealism (Harvard).

Frege, G. (1967). The Basic Laws of Arithmetic, tr., ed. M. Furth (University of California).

- (1968). Foundations of Arithmetic, tr. J.L. Austin (Northwestern University).

Garrett, A. (2007). Meaning in Spinoza's Method (Cambridge).

Garrett, D. (1990). Ethics IP5: Shared attributes and the basis of spinoza's monism, eds. J. A. Cover and M. Kulstad, Central Themes in Early Modern Philosophy: Essays presented to Jonathan Bennett (Hackett), 69-108.

_ (1991). Spinoza's Necessitarianism, in Yovel, 191-218.

— (2002). Spinoza's Conatus Argument, in Koistinen and Biro, 127-58.

— (2012). A Reply on Spinoza's Behalf, in Förster and Melamed, 24864.

(forthcoming). Representation, misrepresentation, and error in Spinoza's philosophy of mind, in Della Rocca.

Gendler, T. and Hawthorne, J. eds. (2002). Conceivability and Possibility (Oxford).

Gennaro, R.J. and Huenemann, C. eds. (1999). New Essays on the Rationalists (Oxford).

Giancotti, E. (1991). On the Problem of Infinite Modes, in Yovel, 97-118.

Gill, M.L. (1989). Aristotle on Substance: The Paradox of Unity (Princeton).

Gueroult, M. (1968/1974). Spinoza, 2 vols. (Aubier-Montaigne). 
Hegel, G.W.F. (1995). Lectures on the History of Philosophy, v.3, tr. E. Haldane (University of Nebraska).

(1969). The Science of Logic, tr. A.V. Miller (Allen and Unwin).

Hübner, K. (2015). On the significance of formal causes in Spinoza's metaphysics, Archiv für Geschichte der Philosophie.

(forthcoming-a). Spinoza's parallelism doctrine: on the connectedness of things, ed. E. Schliesser, Sympathy (Oxford).

(forthcoming-b). Spinoza on negation, mind-dependence and the reality of the finite, ed. Y. Melamed, The Young Spinoza (Oxford).

(forthcoming-c). Spinoza on essences, universals and beings of reason, Pacific Philosophical Quarterly.

Huenemann, C. (1999). The necessity of finite modes and geometrical containment in Spinoza's metaphysics, in Gennaro and Huenemann, 224-40.

Jarrett, C.E. (1977a). The Concept of Substance and Mode in Spinoza, Philosophia 7 (1977):83-105.

(1977b). Some remarks on the 'objective' and 'subjective' interpretations of the attributes, Inquiry 20 (1-4):447-56. (2007). Spinoza: A Guide for the Perplexed (Continuum).

Joachim, H.H. (1901). A Study of the Ethics of Spinoza (Oxford).

Koistinen, O. (2003). Spinoza's proof of necessitarianism, Philosophy and Phenomenological Research 67:2, 283-310.

(1998). On the Consistency of Spinoza's Modal Theory, The Southern Journal of Philosophy 36, 61-80.

(2002). Causation in Spinoza, in Koistinen and Biro, 60-72. and Biro, J. eds. (2002). Spinoza: Metaphysical Themes (Oxford).

Laerke, M. (2011). Spinoza's cosmological argument in the Ethics, Journal of the History of Philosophy, 49:4, 439-62.

Leibniz, G.W. (1875-1890). Die Philosophischen Schriften, ed. C.I. Gerhardt (Weidman).

Philosophical Papers and Letters, ed. L. Loemker (Kluwer 1969).

Lin, M. (2006). Substance, attribute, and mode in Spinoza, Philosophy Compass 1/2, 144-53.

Lewis, D. (1986). On the Plurality of Worlds (Oxford).

Macherey, P. (1979). Hegel ou Spinoza (François Maspero).

Malebranche, N. (1997). The Search after Truth and Elucidations (Cambridge).

Manning, R. (2012). Spinoza's Physical Theory, in The Stanford Encyclopedia of Philosophy (Spring 2012 Ed.), E.N. Zalta (ed.), http:// plato.stanford.edu/archives/spr2012/entries/spinoza-physics/.

Martineau, J. (1882). A Study of Spinoza (Macmillan). 
Melamed, Y. (2009). Spinoza's metaphysics of substance: The substancemode relation as a relation of inherence and predication, Philosophy and Phenomenological Research 78 (1):17-82.

(2010a). Acosmism or weak individuals? Hegel, Spinoza, and the reality of the finite, Journal of the History of Philosophy 48 (1):77-92.

(2010b). Spinoza's Anti-Humanism, eds. J. Smith and C. Fraenkel, The Rationalists. (Springer/Synthese).

- (2012). Spinoza's metaphysics of thought: parallelisms and the multifaceted structure of ideas, Philosophy and Phenomenological Research.

(2013). Spinoza's Metaphysics: Substance and Thought (Oxford).

Nadler, S. (2006). Spinoza's Ethics: An Introduction (Cambridge).

Newlands, S. (2010). The harmony of Spinoza and Leibniz, Philosophy and Phenomenological Research, 81:64-104

_ (2011a) Hegel's idealist reading of Spinoza, Philosophy Compass 6(2), $100-8$.

_ (2011b) More recent idealist readings of Spinoza, Philosophy Compass 6(2), 109-19.

_ (2012). Thinking, conceiving, and idealism in Spinoza, Archiv für Geschichte der Philosophie 94(1).

— (2013). Spinoza's modal metaphysics, in The Stanford Encyclopedia of Philosophy (Winter 2013 Ed.), E.N. Zalta (ed.), http://plato.stanford.edu/ archives/win2013/entries/spinoza-modal/.

Parkinson, G.H.R. (1993). Spinoza and British Idealism: The Case of H.H. Joachim, British Journal of the History of Philosophy 1(1993), 109-23.

Pollock, F. (1880). Spinoza: His Life and Philosophy (C.K. Paul).

Renz, U. (2011). The definition of the human mind and the numerical difference between subjects (2P11-2P135), eds. M. Hampe, U. Renz and R. Schnepf, Spinoza's Ethics. A Collective Commentary (Brill), 99118.

Schaffer, J. (2009). On what grounds what, eds. D. Manley, D.J. Chalmers and R. Wasserman, Metametaphysics: New Essays on the Foundations of Ontology (Oxford).

Schliesser, E. (forthcoming). Spinoza and the philosophy of science: mathematics, motion, and being, in Della Roccca.

Schmaltz, T. (1997). Spinoza's mediate infinite mode, Journal of the History of Philosophy 35, 199-235.

Scruton, R. (2002). Spinoza: A Very Short Introduction (Oxford).

Shein, N. (2009). Spinoza's theory of attributes, Stanford Encyclopedia of Philosophy (Spring 2009 Ed.), E.N. Zalta (ed.), http://plato.stanford.edu/ archives/spr2009/entries/spinoza-attributes 
Spinoza, B. (1984). The Collected Works of Spinoza, vol.1, ed. and tr. E. Curley (Princeton).

(1925). Opera, ed. C. Gebhardt, 4 vols (C. Winter).

(1995). The Letters, tr. S. Shirley, ed. S. Barbone, J. Adler and L. Rice (Hackett).

(2007). Theological-Political Treatise, tr. J. Israel and M. Silverthorne (Cambridge).

Steinberg, D. (1987). Necessity and Essence in Spinoza, Modern Schoolman 64, 187-95.

Viljanen, V. (2011). Spinoza's Geometry of Power (Cambridge).

Wilson, M. (1999). Spinoza's causal axiom (Ethics I, Axiom 4), in Wilson, Ideas and Mechanism: Essays on Early Modern Philosophy (Princeton), 141-65.

Wolfson, H.A. (1934). The Philosophy of Spinoza (Harvard).

Yovel, Y. (ed.) (1991). God and Nature: Spinoza's Metaphysics (Brill). 